\title{
REVERSE INEQUALITIES ON CHAOTICALLY GEOMETRIC MEAN VIA SPECHT RATIO
}

\author{
Masatoshi Fujit, SANG Hun LeE, Yuki SeO AND Dongick Jung
}

Abstract. As an application of Mond-Pečarić method, we shall estimate bounds of operator convexity for convex functions. Consequently, we obtain some order relations between the arithmetic mean and the chaotically geometric one $A \diamond_{\alpha} B$ of positive operators $A$ and $B$, i.e., $A \diamond \alpha B=e^{(1-\alpha) \log A+\alpha \log B}$ for $\alpha \in[0,1]$. Among others, we show that if $0<m \leqslant A, B \leqslant$ $M$ for some scalars $m<M$ and $h=\frac{M}{m}$, then

$$
M_{h}(1)^{-1} A \diamond_{\alpha} B \leqslant A \nabla_{\alpha} B \leqslant M_{h}(1) A \diamond_{\alpha} B
$$

holds for all $\alpha \in[0,1]$, where the Specht ratio $M_{h}(1)$ is defined as

$$
M_{h}(1)=\frac{h^{\frac{1}{h-1}}}{e \log h^{\frac{1}{h-1}}} \quad(h>1) \quad \text { and } \quad M_{1}(1)=1 .
$$

Mathematics subject classification (2000): 47A30,47A63.

Key words and phrases: operator concavity, power mean, arithmetic mean and geometric mean, Löwner-Heinz Theorem, Hölder-McCarthy inequality, Ky Fan-Furuta constant.

\section{REFERENCES}

[1] T. ANDO AND F. HIAI, Log-majorization and complementary Golden-Thompson type inequalities, Linear Algebra Appl., 197, 198 (1994), 113-131.

[2] J. I. FuJII, S. IZUMINO AND Y. SEO, Determinant for positive operators and Specht's theorem, Sci. Math., 1, No. 3 (1998), 307-310.

[3] M. FujiI, T. Furuta And R. Nakamoto, Norm inequalities in the Corach-Porta-Recht theory and operator means, Illinois J. Math., 40 (1996), 527-534.

[4] M. FujII And R. Nakamoto, A gemetric mean in the Furuta inequality, Sci. Math. Japon., 55 (2002), 615-621

[5] T. FURUTA, Extensions of Hölder-McCarthy and Kantorovich inequalities and their applications, Proc. Japan Acad., 73, Ser. A (1997), 38-41.

[6] T. FuRUTA, Operator inequalities associated with Hölder-McCarthy and Kantorovich inequalities, J. Inequal. Appl., 2 (1998), 137-148.

[7] T. FURUTA, Invitation to linear operators, Taylor \& Francis, 2001.

[8] Ky FAn, Some matrix inequalities, Abh. Math. Sem. Univ. Hamburg, 29 (1966), 185-196.

[9] J. Mićić, Y. SEO, S.-E. TAKAHASI AND M. TOMINAGA, Inequalities of Furuta and Mond-Pecaric, Math. Ineq. Appl., 2 (1999), 83-111.

[10] B. Mond AND J. E. PeČARIĆ, Convex inequalities in Hilbert spaces, Houston J. Math., 19 (1993), 405-420.

[11] B. MOND AND J. E. PEČARIĆ, Convex inequalities for several positive operators in Hilbert space, Indian J. Math., 35 (1993), 121-135.

[12] G. K. PEDERSEN, Some operator monotone functions, Proc. Amer. Math. Soc., 36 (1972), 309-310.

[13] W. SPECHT, Zur Theorie der elementaren Mittel, Math. Z., 74 (1960), 91-98. 
[14] M. TominaGa, Specht's ratio in the Young inequality, Sci. Math. Japon., 55 (2002), 583-588.

[15] T. YAMAZAKI AND M. YANAGIDA, Characterizations of chaotic order associated with Kantorovich inequality, Sci. Math., 2 (1999), 37-50. 